\title{
Über eine neue einfache radiochemische Bestimmung von Arginase
}

\author{
Eigenschaften und Verhalten von Arginase im Serum bei Normalpersonen und Leberkranken ${ }^{1}$ )
}

\author{
Von J. Adlung, K. Lorentz und H. Grazikoivske
}

Aus der Röntgen- und Radioisotopenabteilung (Leiter: Prof. Dr. H. Uthgenannt) der I. Medizinischen Klinik

(Direktor: Prof. Dr. U. Ritter) der Medizinischen Akademie Lïbeck

(Eingegangen am 24. Mai 1971)

Die Aktivität von Arginase im Serum kann durch direkte Messung des aus Arginin- $\left[{ }^{14} \mathrm{C}\right]$ gebildeten Harnstoff- $\left[{ }^{14} \mathrm{C}\right]$ bestimmt werden. Das Verfahren erfordert die Trennung von Substrat und Reaktionsprodukt durch zweimalige Fällung von Arginin mit Phosphorwolframsäure, ist wenig arbeitsaufwendig und sehr empfindlich. Mit $100 \mathrm{~mm}$ Arginin und $1 \mathrm{~mm} \mathrm{Mn} \mathrm{Mn}^{2+}$ fanden wir bei $\mathrm{pH} 8,5$ für Normalpersonen Enzymaktivitäten von $6,5 \pm 3,2 \mathrm{U} / 1(\overline{\mathrm{x}} \pm \mathrm{s})\left(37^{\circ}\right)$. Bei schweren Fällen von Hepatitis und dystrophischen Prozessen bei Lebercirrhose ist die Aktivität im Serum erhöht.

\section{A simple radiochemical determination of arginase}

The activity of arginase can be very simply determined in serum by the measurement of the ${ }^{14} \mathrm{C}$-urea formed from ${ }^{14} \mathrm{C}$-arginine. The substrate and reaction product are separated by twice precipitating the arginine with phosphotungstic acid; there are few manipulations and the method is very simple. With $0.1 \mathrm{M}$ arginine, $\mathrm{Mn}^{2+}$ as activator and at $\mathrm{pH} 8.5$, the arginase activity for normal persons was $6.5 \pm 3.2 \mathrm{U} / 1\left(37^{\circ}\right)$. In severe cases of hepatitis and dystrophic conditions in liver cirrhosis, the arginase activity in the serum is increased.

Arginase (I-Arginin-Amidinohydrolase, EC 3.5.3.1) katalysiert die Reaktion

$$
\text { Arginin }+\mathrm{H}_{2} \mathrm{O} \stackrel{\text { Arginase }}{\longrightarrow} \text { Ornithin }+ \text { Harnstoff }(\mathrm{I})
$$

wobei das Reaktionsgleichgewicht weit auf der rechten Seite liegt. Die Enzymaktivität wird daher nur in dieser Richtung nach folgenden Prinzipien bestimmt:

1. Abnahme der Argininkonzentration (chemisch mittels Saxaguchi-Reaktion (1-5) oder durch UVDifferenzspektrophotometrie (6)).

2. Messung der Ornithinbildung (enzymatisch mit Ornithin-Aminotransferase (7) oder chemisch mit Ninhydrin $(8-10))$.

3. Zunahme der Harnstoffkonzentration, wobei entweder Harnstoff selbst durch Reaktion mit Xanthydrol (11-13), Diacetylderivaten (14-20) oder Dimethylaminobenzaldehyd $(21,22)$ gemessen wird, oder die in der gekoppelten Reaktion

$$
\text { Harnstoff }+\mathrm{H}_{2} \mathrm{O} \stackrel{\text { Urease }}{\longrightarrow} \mathrm{CO}_{2}+2 \mathrm{NH}_{3} \text { (II) }
$$

entstehenden Produkte Ammoniak (23-26), $\mathrm{CO}_{2}(27$ bis 29) oder ${ }^{14} \mathrm{CO}_{2}$ aus Guanidino-[14 C]-Arginin (30) bestimmt werden. Die Messung von ${ }^{14} \mathrm{CO}_{2}$ ist auch durch Oxydation von Harnstoff mittels salpetriger Säure mögliç (31).

Während die beiden ersten Verfahren infolge der hohen Michaelis-Konstante des Enzyms für Arginin, starker UV-Absorption durch Proteine, hoher Aminosäurekonzentrationen (die das entstehende Ornithin maskieren) oder durch die Notwendigkeit, das Hilfsenzym anzureichern, keine Bestimmung der Arginase im Serum zulassen, stört beim dritten der Harnstoffgehalt

1) Mit Unterstützung der Volkswagenstiftung und der Deutschen Forschungsgemeinschaft. des Serums die direkten Bestimmungen empfindlich, sofern er nicht durch Gelfiltration $(14,18)$ zuvor entfernt wird.

Im Gegensatz zu diesen aufwendigen oder mit hohen Leerwerten verbundenen Verfahren ist die radiochemische Messung von Harnstoff-[ $\left.{ }^{14} \mathrm{C}\right]$ einfach, spezifisch und bedarf keiner besonderen Isolierungsschritte. Wir möchten im folgenden über ein sehr einfaches Verfahren berichten, das für Routineuntersuchungen mit einem Flüssigkeitsszintillationszähler geeignet ist. Prinzip ist die direkte Messung von Harnstoff-[14 $\mathrm{C}]$ nach Fällung des Arginin-[14 $\mathrm{C}]$ durch Phosphorwolframsäure.

\section{Material und Methodik}

Alle Lösungen wurden, sofern nicht anders vermerkt, aus analysenreinen Substanzen der Fa. Merck (Darmstadt) und Serva (Heidelberg) mit demin. Wasser angesetzt. Guanidino-[ $\left.{ }^{14} \mathrm{C}\right]-$ Arginin (spez. Aktivität $20-40 \mathrm{mC} / \mathrm{mMol}$ ) und Harnstoff- $\left[{ }^{14} \mathrm{C}\right]$ (spez. Aktivität $20-20 \mathrm{mC} / \mathrm{mMol}$.) bezogen wir von Amersham (England). Neben Seren von Gesunden und Leberkranken benutzten wir angereicherte Humanseren mit Zusatz von Arginase aus Rinderleber (Schuchardt, München).

\section{Reagenzien}

1. Arginin $0,22 \mathrm{M}$ in $0,10 \mathrm{M}$ Triäthanolamin, auf $\mathrm{pH} 8,5$ eingestellt.

2. Lösung $1 \mathrm{mit} 50 \mathrm{nC}$ Guanidino- $\left[{ }^{14} \mathrm{C}\right]$-Arginin pro $\mathrm{ml}$.

3. $\mathrm{MnCl}_{2}, 0,05 \mathrm{M}$, gelöst in $0,01 \mathrm{~N} \mathrm{HCl}$.

4. Phosphorwolframsäure 12proz. in 4proz. Trichloressigsäure gelöst.

5. Phosphorwolframsäure 20,7proz. in 4proz. Trichloressigsäure gelöst.

6. BrAY'sche Lösung (32).

\section{Vorgeben}

$0,5 \mathrm{ml}$ Serum werden mit $0,1 \mathrm{ml}$ Manganchloridlösung und $0,5 \mathrm{ml}$ Arginin- $\left[{ }^{14} \mathrm{C}\right]-L o ̈ s u n g ~ b e i ~ 37^{\circ}$ über $3 \mathrm{Stdn}$. (Wasserbad) inkubiert. Unterbrechen der Reaktion durch Zugabe von $3,0 \mathrm{ml}$ 
12proz. Phosphorwolframsäure. Für jeden Analysenwert wird ein Leerwert (Zugabe von Substrat zum Serum unmittelbar vor Fällung mit Phosphorwolframsäure) mitgeführt. Der weißliche Niederschlag wird mit einem Glasstab gut verrührt und anschließend bei $3000 \mathrm{~g} 10 \mathrm{Min}$. zentrifugiert. Das im Überstand verbliebene Arginin- $\left[{ }^{14} \mathrm{C}\right]$ wird durch eine 2 . Fällung eliminiert. Hicrzu werden nacheinander $0,2 \mathrm{ml}$ Argininlösung 1 (ohne Arginin-[ $\left.{ }^{14} \mathrm{C}\right]$ ) und $0,7 \mathrm{ml} \mathrm{20,7proz.} \mathrm{Phosphorwolframsäure} \mathrm{zu-}$ gegeben und wie oben weiter verarbeitet. Vom Überstand werden jeweils $3,0 \mathrm{ml}$ mit $12,0 \mathrm{ml}$ BraY'scher Lösung gemischt und im Flüssigkeitsszintillationszählgerät ( $F$ a. Packard 3380 ) gemessen.

\section{Berechnuing}

Da Zerfälle/Min. gemessen werden, muß auf die spez. Aktivițät des eingesetzten Arginins- $\left[{ }^{14} \mathrm{C}\right]$ (A-dpm/110 $\mu \mathrm{Mol}$.) bezogen werden. A-dpm wird für jede Meßreihe nur einmal durch Verdünnen von $0,5 \mathrm{ml}$ Arginin- $\left[{ }^{14} \mathrm{C}\right]$ (Lösung 2) auf $5,0 \mathrm{ml} \mathrm{mit}$ Wasser und Messung von 3,0 ml Gemisch ermittelt. Die Arginaseaktivität berechnet sich dann aus der Differenz der Zerfälle/Min. aus Analyse und Leerwert ( $\Delta \mathrm{dpm})$, dividiert durch die spezifische Aktivität und multipliziert mit den Faktoren für das Serumaliquot $(=2000)$ und die Inkubationszeit $(=1 / 180)$ nach

$$
\begin{aligned}
\mu \text { Mol Harnstoff } \cdot \mathrm{I}^{-1} \cdot \mathrm{Min}^{-1} & =\mathrm{dpm} \cdot \frac{2000 \cdot 110}{180 \cdot \mathrm{A}-\mathrm{dpm}} \\
\mathrm{U} / \mathrm{l} & =1220 \cdot \frac{\Delta \mathrm{dpm}}{\mathrm{A}-\mathrm{dpm}}
\end{aligned}
$$

\section{Ergebnisse : ,}

\section{Fällung, Wiederfindung, Empfindlicbleit}

Neben einer vollständigen Enteiweißung ist die komplette Entfernung von Arginin aus dem Reaktionsansatz unumgänglich. $\mathrm{Da}$ ein $z u$ hoher Überschuß an Phosphorwolframsäure die Messung in Bray'scher Lösung unmöglich macht, ermittelten wir deren optimale Menge (mg pro Ansatz) durch Zusatz steigender Phosphorwolframsäure-Konzentrationen zum Gemisch aus Serum und Arginin. Die Wiederfindung von Harnstoff wurde mit verschiedenen Seren überprüft. Hierzu wurde die ${ }^{14} \mathrm{C}$-Aktivität in der Argininlösung-[ $\left.{ }^{14} \mathrm{C}\right]$ durch Harnstoff-[14 C] ersetzt. Die Wiederfindung lag immer über $95 \%$.

Abbildung 1 und 2 zeigen die Abhängigkeit der Harnstoffbildung von der Konzentration an Mangan und Arginin. Die Aktivierung der Arginase im Serum beginnt erst oberhalb $1 \mathrm{~mm} \mathrm{Mn}^{++}$, das Substratoptimum für Arginin liegt bei $0,1 \mathrm{M}$. Höhere Konzentrationen hemmen gering.

\section{Eigenschaften menschlicher Serum-Arginase}

Mit der beschriebenen Methode ist Arginase im menschlichen Serum immer nachweisbar. Die Harnstoffbildung aus Arginin folgt über mindestens 6 Stunden einer Funktion nullter Ordnung (Abb. 3). Eine Enzymaktivität von 2,5 U/1 kann noch sicher nachgewiesen werden (Analysenwert größer als Leerwert +2 Standardabweichungen, $\mathrm{n}=30$ ).

Die Abhängigkeit vom $\mathrm{pH}$-Wert wurde mit verschiedenen Puffern (Phosphat 0,2M, Triäthanolamin 0,2M, Glycin $0,2 \mathrm{M}$, Tris $0,1 \mathrm{M}$ ) in insgesamt 5 verschiedenen Seren untersucht. Eine typische Kurve ist in Abbildung 4 wiedergegeben. Das Optimum lag in allen Fällẹn bei pH 8,5. Die Bestimmung der Enzymabhängigkeit wurde wegen der geringen Serumaktivität mit ange- reicherten Seren durchgeführt. Die Harnstoffbildung läuft der zugegebenen Enzymmenge bis zum 40 fachen der durchschnittlichen normalen Serumkonzentration proportional (Abb. 5).

\section{Normwerte, klinische Auswertung}

Aus Untersuchungen an 50 Seren von Gesunden errechneten wir für die' Arginaseaktivitäten im menschlichen Serum einen Normalwert vion $6,5 \pm 3,2$ U/1. Bei

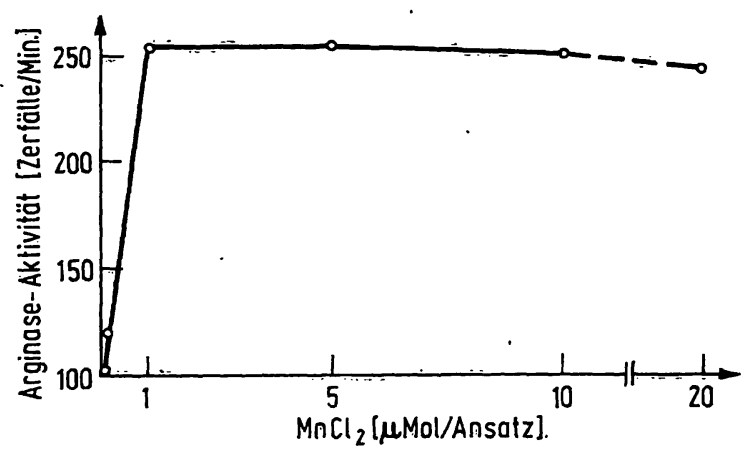

Abb. 1

Abhängigkeit der Arginase-Aktivität im Serum von der $\mathrm{Mn}^{++}$-Konzentration. Serum einer gesunden Versuchsperson

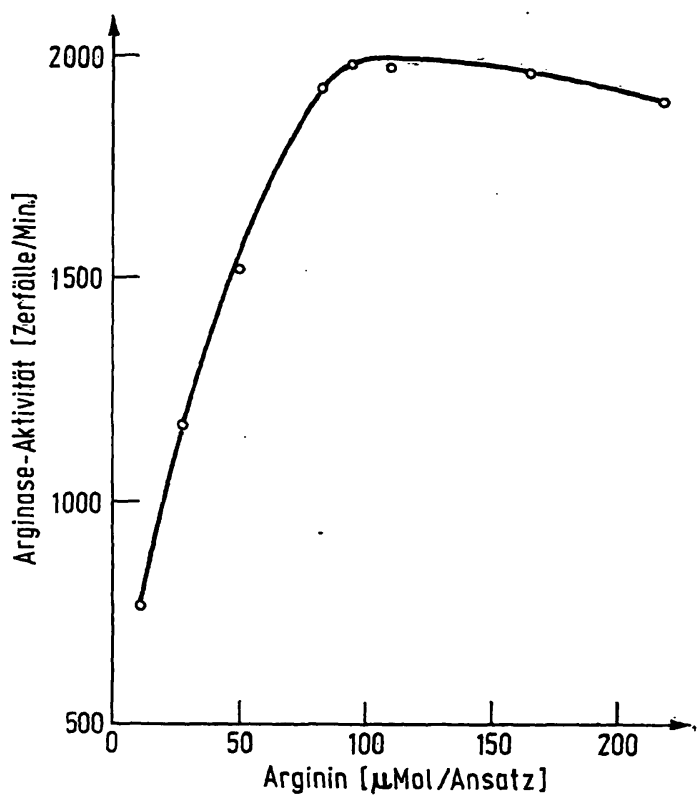

Abb. 2

Substratabhängigkeit. Ordinate $=$ Harnstoff-[24C]-Aktivität $(\Delta \mathrm{dpm})$ Abszisse steigende Argininkonzentrationen

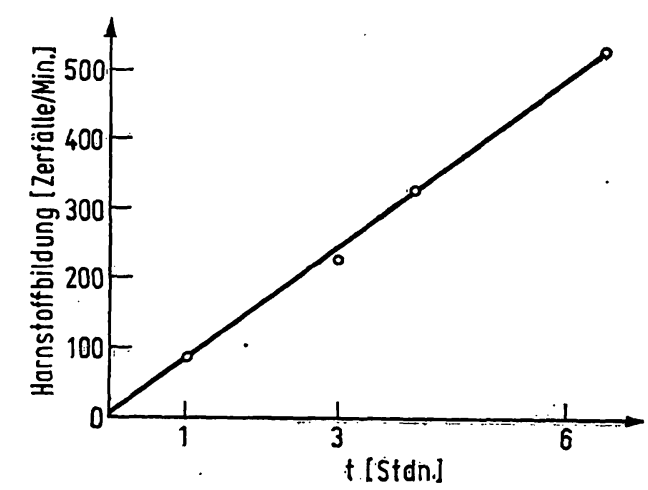

Abb. 3

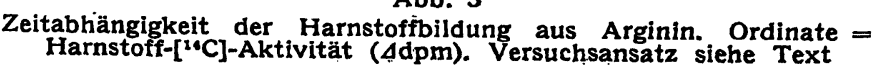




\section{Auch die kleinste Bestellung wird von uns wie ein großer Auftrag behandelt.}

Eine Ratte - drei Tage schwanger. Eine männliche Maus - 18-20 gr. schwer. Oder irgendeine Maus oder Ratte nach Ihren speziellen Wünschen.

Wir sind für jede Bestellung dankbar, egal ob sie groß oder klein ist. Dafür liefern wir Ihnen die besten Versuchstiere, die Sie kaufen können. Diese Tiere werden unter denselben gewissenhaften Bedingungen gezüchtet, die von den Charles River Laboratorien in ganz Nord-Amerika gestellt werden.

Da dies die besten und gesündesten Tiere sind, die zur Verfügung stehen, benötigen sie keine besonderen Behausungen, um einheitlichere Forschungsergebnisse zu erzielen. Das bedeutet, dass die Auswertung der wissenschaftlichen Fakten äuBerst präzise ist. Wàs wollen Sie mehr?

Die Arche Noah nahm immer nur zwei Tiere auf: Wir verschicken unsere Versuchstiere auch einzeln-oder soviele wie Sie wollen. Ein Anruf genügt:

(35) 7718.87 .

\section{Charles River Aubin-les-Elbeuf / France S.A.}

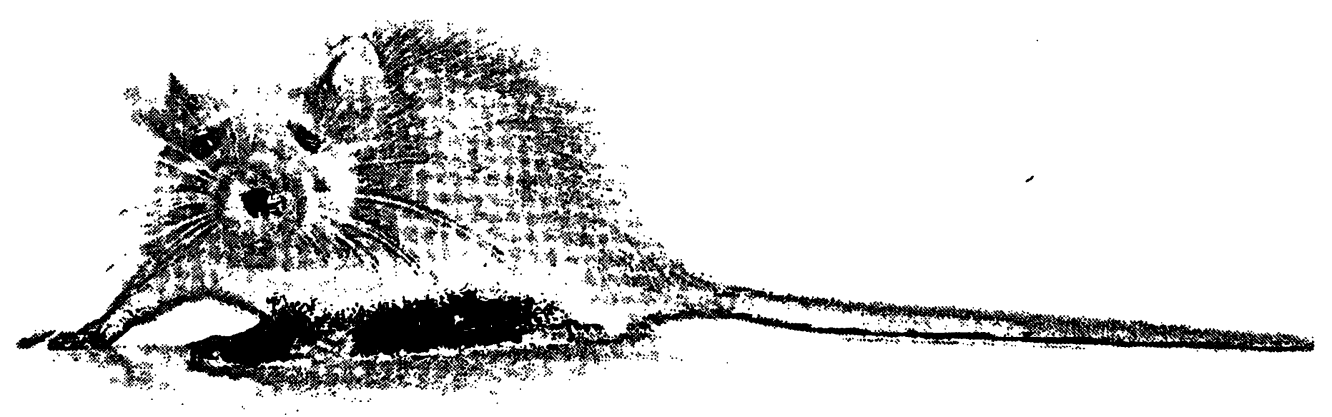




\section{eine Tür ging auf zu einem modernen Programm!}

\section{Heißluft-Sterilisatoren Inkubatoren mit Wassermantel wasserfreie Inkubatoren thermostatisierte Wasserbäder}
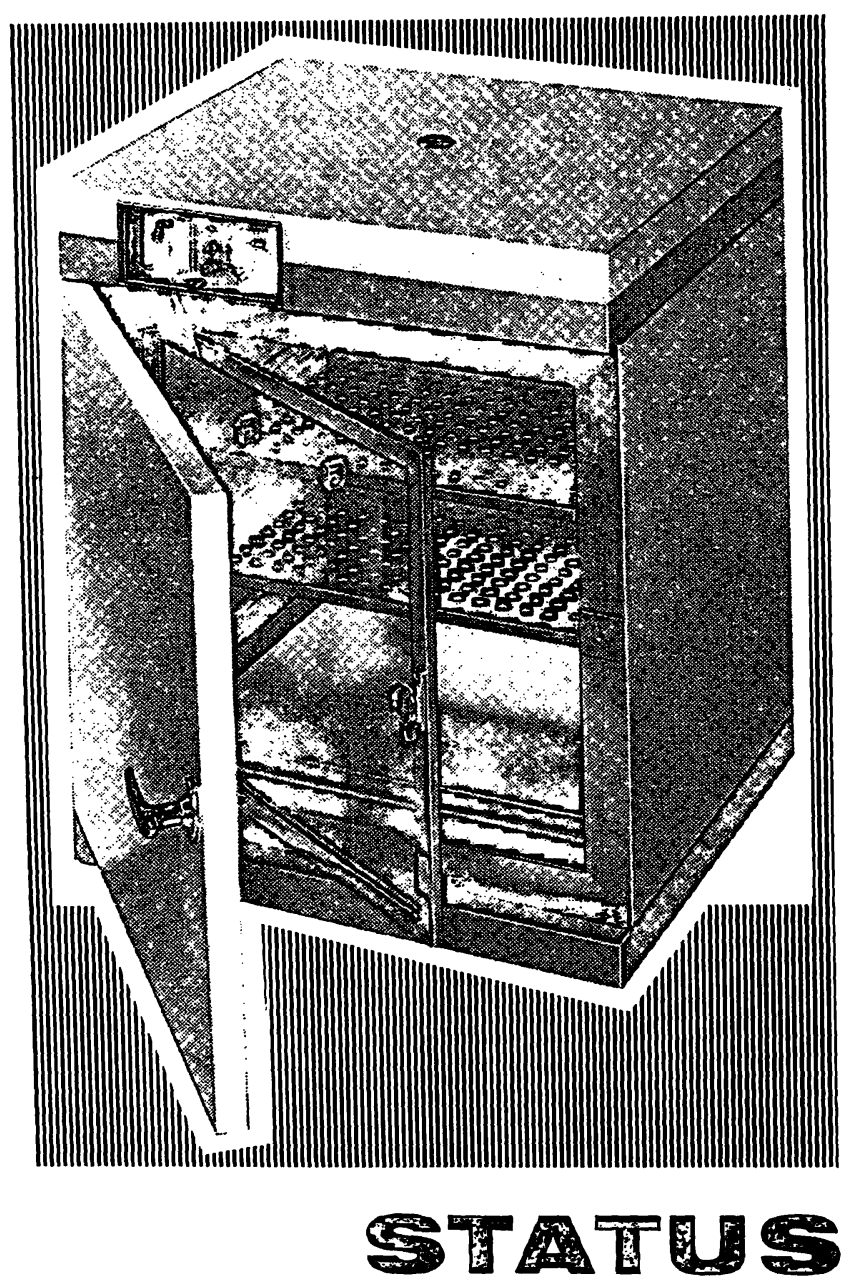

korrosionsfreie Laborgeräte

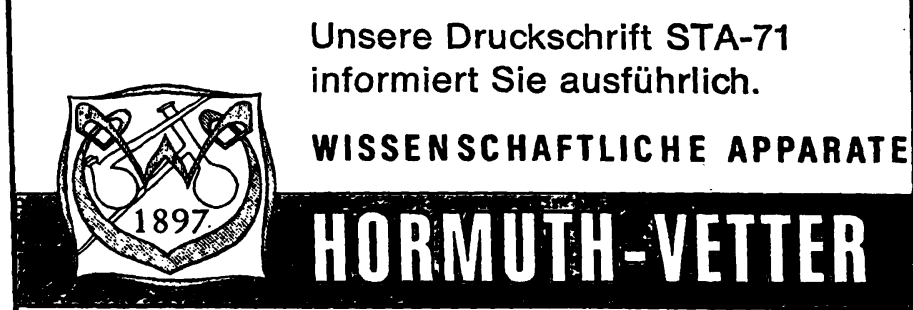

6908 Wiesloch/Bd., Postfach 1348, Tel. 06222/21 47 6900 Heidelberg 1, Postfach 750, Tel. 0622120045

\section{Gastrokamera-}

\section{Untersuchung}

\author{
Grundlagen
}

Untersuchungstechnik, Bildbeurteilung, Ergebnisse

mit den Referaten des Ersten Gastrokamera-Seminars, 13.-15. Juni 1969, Berlin

\section{Herausgegeben}

\section{von Dozent Dr. H. Oshima}

Gastprofessor an der Freien Universität Berlin, Nippon-IkaUniversität Tokyo,

Präsident der European Association for Gastrokamera Diagnosis, unter Mitarbeit von Dr. W. BergemanN, Berlin

Oktav. VIII, 146 Seiten. Mit 33 Abbildungen. 1971.

Kartoniert DM 20,-

Die Gastrokamera-Untersuchung, ein schnelles, einfaches und beschwerdearmes Verfahren zur intragastralen farbigen Fotografie für die Magen-Diagnostik hat in Europa in den letzten Jahren eine zunehmende Bedeutung erlangt.

Vom 13.-15. 6. 1969 wurde das Erste Gastrokamera-Seminar im Klinikum Steglitz der Freien Universität Berlin veranstaltet.

Die verschiedenen Gastrokamera-Modelle, die Untersuchungstechnik und besonders die Beurteilungsmethode sowie -kriterien wurden als Schwerpunkte behandelt.

Durch die Berichte der verschiedenen Untersucher aus 6 europäischen Ländern wurde der derzeitige Stand der GastrokameraDiagnostik in Europa dargelegt.

Die etwa 300 Teilnehmer aus 9 europäischen Ländern bewiesen das rege Interesse an dieser Untersuchungsart.

An einer weiter zunehmenden Bedeutung dieses diagnostischen Verfahrens ist bei der Häufigkeit von Magenerkrankungen, insbesondere des Magenkrebses nicht zu zweifeln. Dazu soll die Herausgabe dieser Verhandlungsberichte als Leitfaden der Gastrokamera-Untersuchung beitragen.

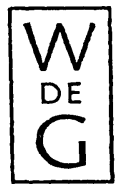


ARBEITSMETHODEN

DER MODERNEN NATURWISSENSCHAFTEN

Herausgegeben von Prof. Dr. Kurt FrschBrCK

\section{KONRAD DORFNER}

\section{Ionenaustauscher}

\section{Auflage}

Mit 100 Abbildungen, 27 Tabellen im Text und 1 Tabellenanhang (mit 19 Tabellen). Oktav. XII, 320 Seiten. 1970. Plastikeinband DM 58,-

Nach der erweiterten Einführung wird eine ausführlichere Darstellung der verschiedenen Ionenaustauschertypen sowie ibrer Eigenschaften und Prüfmethoden gegeben. Besonders über die Verwendung der Ionenaustauscher in der Technik wird im einzelnen berichtet, um den Neuentwicklungen gerecht $\mathrm{zu}$ werden. So sind die rechnerische Behandlung und die speziellen Verfahren des Festbettverfabrens, die neuesten Entwicklungen der kontinuierlichen Verfahren, die Wasseraufbereitung mit Ionenaustauschern und die Verwendung der Ionenaustauscher zur Abwasserreinigung, Metallgewinnung, Zuckerherstellung und sonstiger technischer Anwendungen in dem vorgegebenen Rahmen so umfassend wie möglich dargestellt worden. Die übrigen Kapitel wurden nach den neuesten Ergebnissen durchgearbeitet, verbessert und ergänzt.

\section{JohanNes FlüGge \\ Grundlagen der Polarimetrie}

Gerätekunde und Meßtechnik

Oktav. Mit 72 Abbildungen und 28 Tabellen. XI, 159 Seiten. 1970. Plastikeinband DM 48,-

Wurde die Polarimetrie beteits seit langem als analytisches Verfahren, z. B. in Zuckerfabriken und in Betrieben der pharmazeutischen Chemie, angewandt, so hat sie sich in neuerer Zeit auch in der Erforschung von Molekülstrukturen als aufschlußreich erwiesen, besonders seitdem es automatische und Spektralpolarimeter bis ins Ultraviolett gibt. Das vorliegende Werk informiert über Grundlagen, Meßtechnik und moderne Geräte dieser optischen Methode und berücksichtigt ihren Stand bis in die jüngste Zeit, wobei neben der Analytik auch die Bestimmung der Rotationsdispersion, der magneto-optischen Drehung des Lichts und der Elliptizität, wie sie bei Zirkulardichroismus aưftritt, besprochen werden. Photoelektrische Polarimeter und Saccharimeter werden ausfübrlich behandelt.

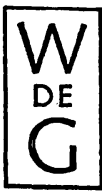

Walter de Gruyter

Berlin $\cdot$ New York

\section{Mit sechzehn Rotoren kann eine automatische* RC-3 Kühlzentrifuge ausgestaltet werden.}

* automatisch, wie z. B. die

Blutaufbereitung in 2 Minuten

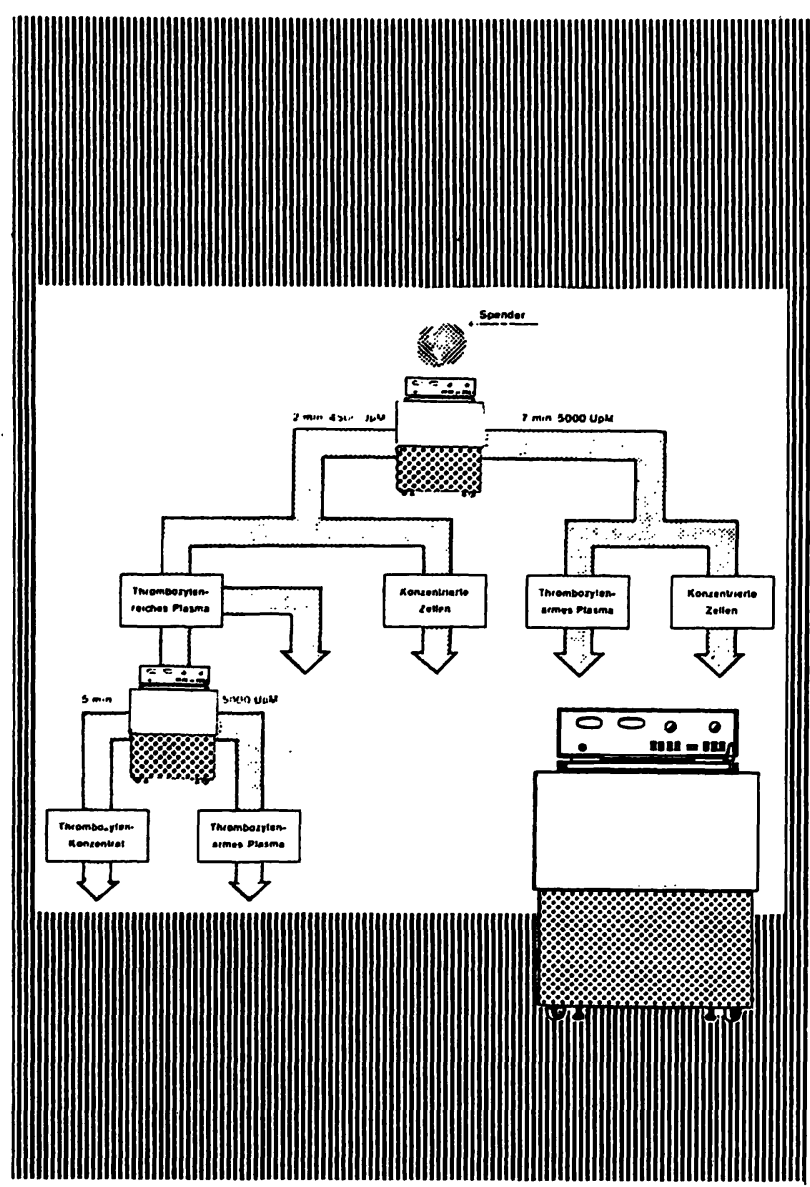

Kennen Sie das übrige Zentrifugen-Programm?

\section{Unsere interessante}

Druckschrift RC 3-702

informiert Sie ausführlich.

WISSEN SCHAFTLICHE APPARATE

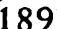

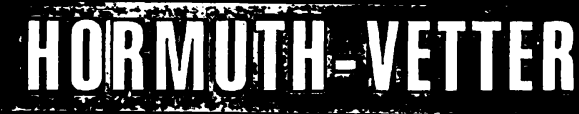

6908 Wiesloch/Bd., Postf. 1348, Tel. 06222/2147

6900 Heidelberg 1, Postf. 750, Tel. 06221/20045 


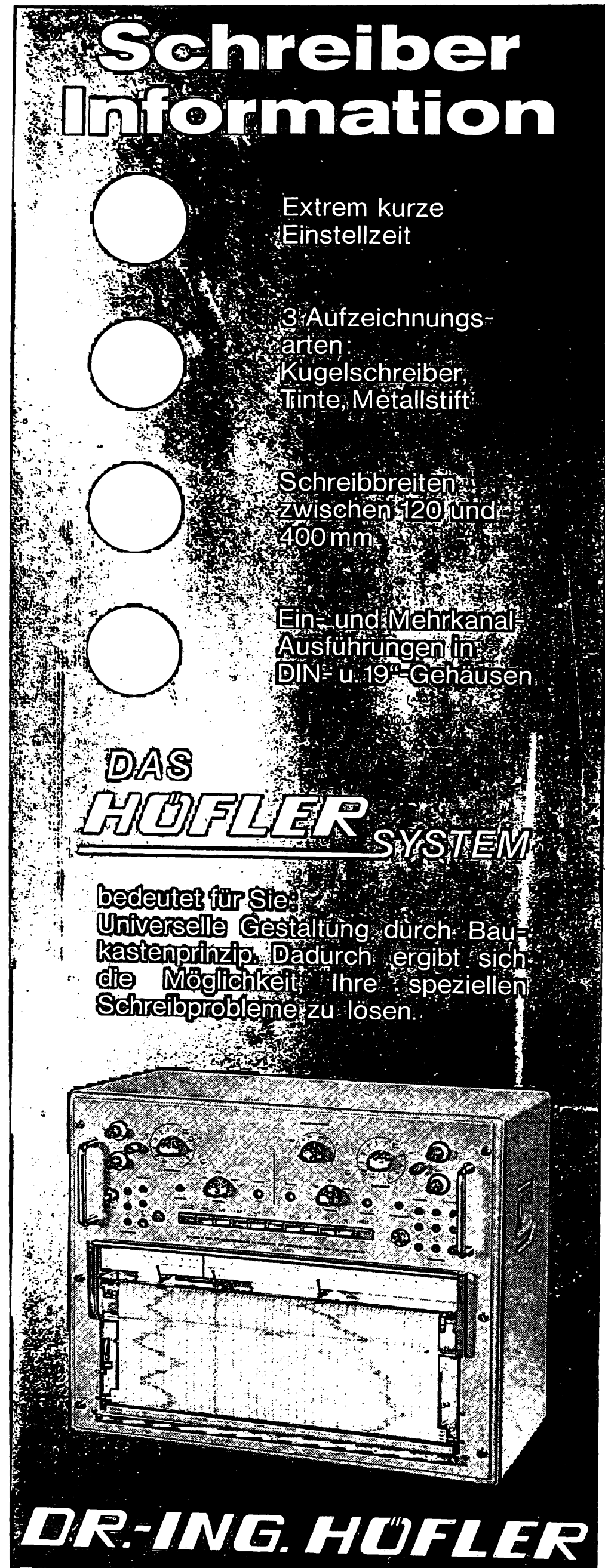

\title{
Autoradiography
}

by

\author{
Dipl.-Chem. Helmut A. Fischer \\ Max-Planck-Institute for Brain Research, \\ Neurochemical Research Group, \\ Frankfurt/Main \\ and
}

\section{Prof. Dr. Gottfried Werner}

Max-Planck-Institute for Brain Research, Neurochemical Research Group,

Frankfurt/Main

Octavo. X, 198 pages. With 93 figures and 14 tables. 1971. Bound DM 64, -; $\$ 18.80$ (Working Methods in Modern Science. Edited by Prof. Dr. Kurt Fischbeck)

\begin{abstract}
"Autoradiography" describes the methods and techniques, possibilities and limitations, of the qualitative and quantitative autoradiography of macroscopic, microscopic and electron-microscopic specimens. The book is of interest to all those working with radioisotopes in scientific and medical fields and to all scientific and technical libraries, institutes, clinics and all laboratories of scientific subjects.
\end{abstract}

Weiterhin lieferbar:

Fischer-Werner, Autoradiographie. Mit 93 Abbildungen und 14 Tabellen. X, 214 Seiten. 1971. Gebunden DM 42, -

(Arbeitsmethoden der modernen Naturwissenschaften. Herausgegeben von Prof. Dr. Kurt Fischbeck).

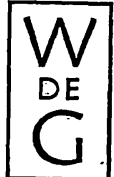




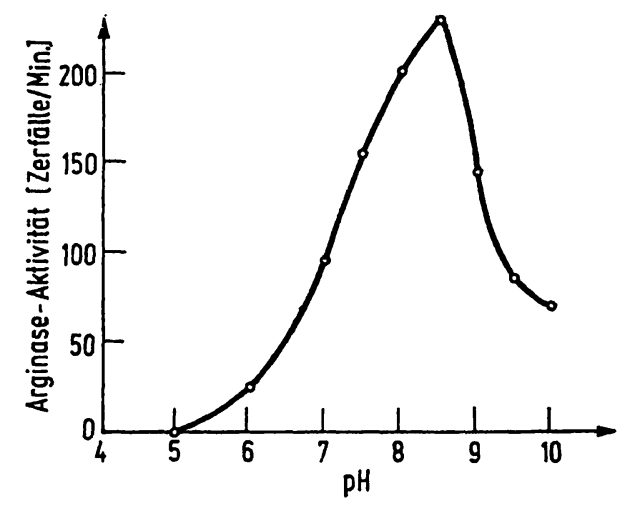

Abb. 4

pH-Abhängigkeit. Bestimmungsansatz siehe Text

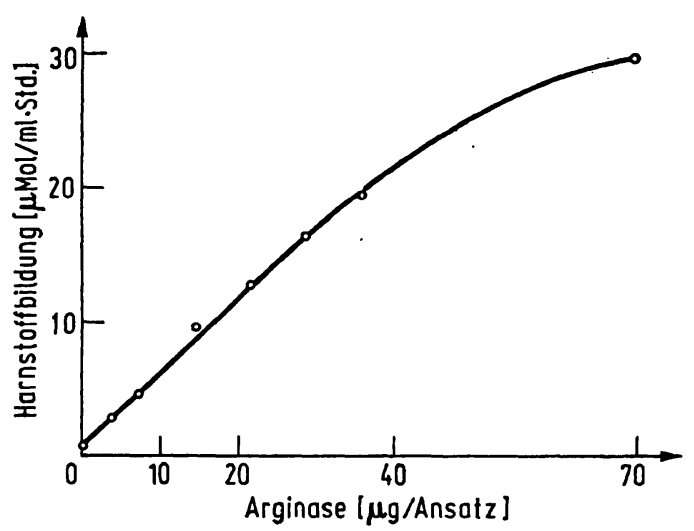

Abb. 5

Abhängigkeit der Harnstoffbildung aus Arginin von der Enzymkonzentration. Im Ansatz (siehe Text) steigende Konzentrationen von Arginase aus Rinderleber

19 Fällen von Lebercirrhose fanden wir $10 \mathrm{mal}$ eine Erhöhung über den 2s-Bereich. Dabei ergab sich keine Korrelation mit der Höhe der Transaminasen oder der alkalischen Phosphatase. Bei 5 Fällen von fortgeschrittener dekompensierter Lebercirrhose waren die Transaminasen normal, die Arginase erhöht, bei den übrigen Fällen mit erhöhter Arginase die Transaminasen mäßiggradig erhöht, die Aspartat-Aminotransferase immer deutlicher als die Alanin-Aminotransferase.

Bei 22 Fällen von akuter Hepatitis wurde $17 \mathrm{mal}$ eine erhöhte Arginase gefunden. Auch hier war statistisch keine Korrelation mit der Höhe der Transaminasen zu sichern. Bei Transaminasewerten oberhalb $200 \mathrm{U} / 1$ ( $n=11$ ) fand sich nur $2 \mathrm{mal}$ eine nicht erhöhte Arginase. Bei Transaminasewerten zwischen 50-200 U/1 $(\mathrm{n}=7)$ war die Arginase $5 \mathrm{mal}$ normal.

\section{Diskussion}

Eine direkte Bestimmung von Harnstoff-[14 $\mathrm{C}]$ setzt die völlige Eliminierung. von Arginin-[14 $\mathrm{C}]$ voraus. Zur Erzielung ausreichend niedriger Leerwerte ist daher eine zweimalige Fällung mit Phosphorwolframsäure erforderlich. Da Harnstoff die Enzymreaktion nicht hemmt (22), ist die Harnstoffbildung aus Arginin unabhängig von der Höhe des endogenen Harnstoffspiegels.

Die von uns ermittelte optimale Substratkonzentration (0,1 M Arginin) liegt etwas höher als die der meisten Untersucher (13, 18, 22, 33, 34). Allerdings werden verschiedentlich noch höhere Konzentrationen angegeben $(19,31)$. Die meisten Untersucher inkubieren bei pH 9,5 (9,0-9,9), dem Optimum der Arginase aus tierischer Leber $(10,14,18,22,25,26,30,33,34)$. Das $\mathrm{pH}-$ Optimum von Arginase im Humanserum liegt mit allen geeigneten Puffern bei pH 8,5.

Im Serum läßt sich ohne Mangan keine Aktivität nachweisen, dagegen bei Zusatz des Aktivators in jedem Fall $(n=136)$. Die Reaktion folgt über einen großen Bereich einer Funktion nullter Ordnung und ist daher auch für die Bestimmung von hohen Arginaseaktivitäten (z. B. in Leberhomogenaten) geeignet.

Die von uns im Serum ermittelten Werte liegen etwas höher als die der meisten Voruntersucher (13, 18, 20, $25,30,33,34$ ), aber in der gleichen Größenordnung wie die von DARger (26) und von Jergovic und Mitarbeitern (22). Einige Untersucher finden keine Arginaseaktivität im Serum von Normalpersonen $(14,15,25,35)$, andere müssen zum Nachweis 6-24 Stunden inkubieren $(13,36)$. Alle genannten Autoren untersuchen bei pH 9,5 oder höheren Werten, zum Teil ist die Streuung erheblich $(4,17)$.

Unsere bisherigen Beobachtungen lassen in Ubereinstimmung mit verschiedenen Voruntersuchern $(25,34$, 37-42) den Schluß zu, daß eine Erhöhung von Arginase im Serum Leberkranker vorwiegend bei dystrophischen Prozessen auftritt. Wir fanden allerdings eindeutig erhöhte Werte auch bei fortgeschrittenen dekompensierten Lebercirrhosen mit nur gering erhöhten Transaminasen. Im Vergleich zu den Transaminasen ist die Arginase bei allen anderen Lebererkrankungen jedoch offensichtlich weniger empfindlich. $\mathrm{Ob}$ das Enzym spezifisch für einen Leberschaden ist $(18,25,34,39)$, kann von uns nicht entschieden werden. Cornelius und Mitarbeiter (37) sowie Pelikan und Mitarbeiter (39) sind der Meinung, daß der Wert der Arginasebestimmung bei Leberkranken in der Verlaufs- und Prognosebeurteilung liegt und aus einem Anstieg auf das Vorliegen von nekrotisierenden Prozessen geschlossen werden kann. Auch diese Feststellung erscheint uns aufgrund unserer Untersuchungen problematisch.

\section{Literatur}

1. Gilboe, D. D. und J. N. Williams, Proc. Soc. Exper. Biol. Med. (N. Y.) 91, 535 (1956). - 2. GmboE, D. D. und J. N. Williams, Proc. Soc. Exper. Biol. Med. (N. Y.) 91, 537 (1956). 3. Iyer, S. N. und C. R. Krishina-Murti, Experientia, (Basel) 8 , 308 (1952). - 4. Lozb, W. F. und R. A. Stuhlman, Clin. Chem., (N. Y.) 15, 162 (1969). - 5. Mansurova, J. D. und L. G. KALETKina. Lab. Djelo 4, 219 (1969). - 6. WARD, R. L. und P. A.
SRERE, Analytic. Biochem. 18, 102 (1967). - 7. HirsCh-Kolb, H. und D. M. Greenserg, Analytic. Biochem. 35, 60 (1970). 8. Roman, W., J. RuYs und R. C. S. Oon, Enzymol. biol. clin. 10, 354 (1969). - 9. Rossi, N. und E. GrAzI, European J. Biochem. 7, 348 (1969). - 10. BLECH, W. Z. exper. Med. 144, 134 (1967). - 11. EdLbachier, S. und H. Röthler, Hoppe-Seyler's Z. physiol. Chem. 148, 264 (1925). - 12. GreenderG, D. N., in: 
S. P. Colowick und N. O. Kaplan. Methods in Enzymology, II 368. Academic Press, New York (1955). - 13. VIncent, D. und G. Segonzac, Rev. Franc. Etudes Clin. Biol. 5, 390 (1960). 14. Cornelius, Ch. E. und R. A. Freedland, Cornell Vet., (Ithaca) 52, 344 (1962). - 15. Forsell, C. M. und J. P. Palva, Scand. J. clin. laborat. invest. 13, 131 (1961). - 16. Kumate, J., v. BenAvides, J. Carillo, M. Santos und L. Ranget, J. Infect. Dis., (Chicago) 103, 25 (1958). - 17. ManNing, R. T. und S. Grisolia, Proc. Soc. Exper. Biol. Med., N. Y. 95, 225 (1957). - 18. MelleRUP, B., Clin. Chem., (New York) 13, 900 (1967). - 19. SatoH, P. S. und Yoker Ito, Analytic. Biochem. 23, 219 (1968). - 20. ZAPF, P. W., Clin. chim. Acta, (Amsterdam) 26, 547 (1969). 21. Hagan, J. J. und R. D. Dallam, Analytic. Biochem. 22, 518 (1968). - 22. Jergovic, I., Ivana Žužrc, MariJana FišerHerman und B. Straus, Clin. chim. Acta, (Amsterdam) 30, 765 (1970). - 23. Hunter, A. und J. A: Dauphinee, Proc. Roy. Soc. Lond. Ser. B 97, 209 (1924). - 24. Hunter, A. und C. E. Downs, J. biol. Chemistry 155, 173 (1944). - 25. UgarTe, G., M. E. Pino, P. Peirano und E. Marusić, J. Laborat. Clin. Med., (S. Louis) 55, 522 (1960). - 26. DARGEL, R., diese Z. 4, 36 (1966). -
27. Werr, L. und M. A. Russerl, J. biol. Chemistry 106, 505 (1934). - 28. Hunter, A. und J. B. Petrigrew, Enzymologia 1, 341 (1936). - 29. Slyyke van, D. D. und R. M. Archibald, J. biol. Chemistry 165, 293 (1946). - 30. Carulli, N., Analytic. Biochem. 24, 515 (1968). - 31. RrGHeTrI, P., L. DE LUCA und G. Wolf, Analytic. Biochem. 22, 225 (1968). - 32. BRAX, G. A., Analytic. Biochem. 1, 279 (1960). - 33. FišER-Herman, F., pers. Mitt. - 34. Pelikin, V., M. Kaldís und J. Trchy, Clin. chim. Acta, (Amsterdam) 9, 141. (1964). - 35. Friedman, M. M. und E. Beckek, Clin. Chem., (New York) 1,2,110 (1955). - 36. Clark, L. C., jr. und E. I. Beck, J. Appl. Physiol. 2, 343 (1949). - 37. Cornelius, C. E., G. M. Douglas, R. R. Gronwall und R. A. Freedland, Cornell Vet., (Ithaca) 53, 181 (1963). - 38. McLEAN, P. und F. Rossr, Biochem. J. 91, 261 (1964). - 39. Pelrkán, V., M. KaLÁB und J. Novosadoví, Dtsch. Zschr. Verdauungskrkh. 23, 151 (1963). - 40. Pélíkín, V., M. Katáb und M. Sinoflak, Z. exper. Med. 139, 278 (1965). - 41. Ugarte, G., M. E. Pino und J. Valenzuela, J. Laborat. Clin. Med., (S. Louis) 57, 359 (1961). - 42. Ugarte, G., M. E. Pino, J. Valenzuela und F. LorcA, Gastroenterology, (Baltimore) 45, 182 (1963).

Priv.-Doz. Dr. J. Adlung

I. Medizinische Klinik der Med. Akademie Lübeck 24 Lübeck

Kronsforder Allee 71-73 